Viso - Cadernos de estética aplicada

Revista eletrônica de estética

ISSN 1981-4062

№ 8, jan-jun/2010

http://www.revistaviso.com.br/
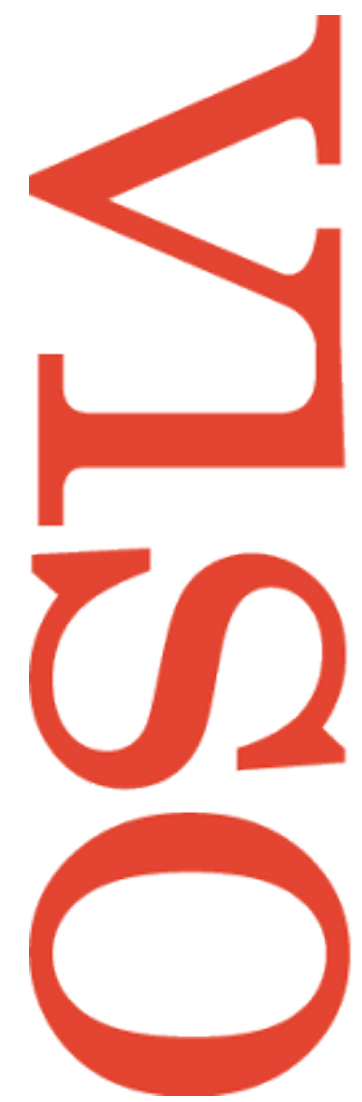

\title{
O sobrevoo (des)engajado de Jacó Guinsburg Pedro Caldas
}




\section{RESUMO}

\section{O sobrevoo (des)engajado de Jacó Guinsburg}

A proposta de Rosangela Patriota e Jacó Guinsburg em "A Cena em aula" consiste em apresentar ao leitor, mediante uma abodagem ampla, as lições de Jacó Guinsburg sobre teoria e estética teatral. O livro consiste em uma coleção de documentos, tais como: notas de aula, registros de aulas, e uma entrevista com o prof. Guinsburg, que servem de testemunhos de seus cursos na Universidade de São Paulo. O livro pode ser lido como um retrato da cultura brasileira em um momento específico, mas também como uma aula de dinamismo e de teoria das idéias em crítica teatral.

Palavras-chave: Estética teatral - curso sobre teatro - Jacó Guinsburg

\section{ABSTRACT}

Jaco Guinsburg's (dis)engaged flight

Rosangela Patriota and Jaco Guinsburg's purpose in "A Cena em aula" is to present the reader with a comprehensive aprroach of Jaco Guinsburg's lessons on theory and aesthetics of theater. The book is a collection of documents, such as: lesson notes, lesson recordings and a interview with Prof. Guinsburg, which serves as testimonial of his courses at the University of São Paulo. One can read the book as a portrait of a specific moment of the brazilian cultural history, but also as a course on dynamic lecturing and theory of ideas in theatrical criticism.

Keywords: Theatrical aesthetics - Lectures on theatre - Jacó Guinsburg 
CALDAS, P. "O sobrevoo (des)engajado de Jacó Guinsburg". In: Viso: Cadernos de estética aplicada, v. IV, n. 8 (jan-jun/2010), pp. 41-49.

DOI: 10.22409/1981-4062/v8i/85

Aprovado: 01.06.2010. Publicado: 10.07.2010.

(C) 2010 Pedro Caldas. Esse documento é distribuído nos termos da licença Creative Commons Atribuição-NãoComercial 4.0 Internacional (CC-BY-NC), que permite, exceto para fins comerciais, copiar e redistribuir o material em qualquer formato ou meio, bem como remixá-lo, transformá-lo ou criar a partir dele, desde que seja dado o devido crédito e indicada a licença sob a qual ele foi originalmente publicado.

Licença: http://creativecommons.org/licenses/by-nc/4.0/deed.pt_BR

Accepted: 01.06.2010. Published: 10.07.2010.

(C) 2010 Pedro Caldas. This document is distributed under the terms of a Creative Commons Attribution-NonCommercial 4.0 International license (CC-BY-NC) which allows, except for commercial purposes, to copy and redistribute the material in any medium or format and to remix, transform, and build upon the material, provided the original work is properly cited and states its license.

License: http://creativecommons.org/licenses/by-nc/4.0/ 
PATRIOTA, R.; GUINSBURG, J. (orgs). J. Guinsburg, a Cena em aula: Itinerários de um professor em devir. São Paulo: EDUSP, 2010.

Caso queira aproveitar ao máximo "J. Guinsburg, a Cena em aula", livro organizado por Rosangela Patriota sobre a obra de Jacó Guinsburg, o leitor deverá dedicar mais concentração do que a habitualmente emprestada aos prólogos. Lá poderá encontrar a preciosa dica de João Roberto Faria, elegante o suficiente para nos avisar: "[..] este livro é um autêntico curso de estética teatral, que devemos ler devagar, aos poucos, para que os ensinamentos da cada página sejam assimilados de maneira metódica e consistente" (p. 20). Claro, todo livro feito com esmero - e este é o caso da obra que tenho em mãos - exige atenção. Mas, neste volume, organizado por Rosangela Patriota, professora do Instituto de História da Universidade Federal de Uberlândia e grande especialista em história do teatro brasileiro, a trajetória intelectual de Jacó Guinsburg aparece sob várias formas: diálogos, apontamentos, depoimentos, entrevistas, traduções. Destacar esta ou aquela face seria empobrecer e reduzir a experiência do professor e todo o trabalho de Rosangela e de sua equipe, razão pela qual me arrisco a apresentar a obra por alguns ângulos de leitura.

O leitor tem, nas páginas de "A aula, a cena e o mestre", o ângulo da sala de aula. Podemos voltar a 1985, momento em que Jacó Guinsburg e seus alunos debatem teatro, e, imagino, saem com a certeza de que, se não estivessem juntos, não teriam chegado às conclusões e, mais ainda, às dúvidas formuladas. Quem já esteve à frente de uma turma de alunos sabe muito bem que certas ideias, apesar do esmero no preparo, jamais poderiam ter sido planejadas, e tampouco teriam sido registradas em silêncio, pela primeira vez, na forma da silenciosa palavra escrita em um artigo ou em um livro; precisavam ser ditas, trocadas, nascidas em público e com o público. Felizmente, no livro organizado por Rosangela Patriota, o leitor tem a chance de ler um diálogo, o registro da sala de aula, raro, quase uma relíquia. Mas, ao contrário de relíquias, não é preciso espanar sua poeira para torná-lo visível. O leitor é um ouvinte da aula - que, decerto, gostaria de estender sua mão para fazer uma pergunta ao Professor Jacó Guinsburg.

Se este resenhista lá estivesse, certamente perguntaria pela importância da filosofia de Hegel em algumas das intervenções de Jacó Guinsburg. Já a presença da palavra "devir" no subtítulo do livro levanta a suspeita da presença de um agradável sotaque hegeliano, igualmente presente na visão histórica do professor. Exemplo: em resposta a uma pergunta de Abílio Tavares, Jacó Guinsburg diz:

Na verdade, cada concepção tem seus antepassados. É assim que vamos a Aristófanes e encontramos Brecht, vamos à farsa medieval e encontramos Brecht, vamos a Büchner e encontramos teorização e quase a efetivação do procedimento brechtiano. Mas isto é feito a posteriori [...] (p.47).

Claro está que a apreensão de Hegel feita por Jacó Guinsburg não ocorre na chave ilustrativa, em que a arte perde parcialmente sua autonomia e é um veículo da história da 
descoberta que o Espírito faz de si mesmo, de sua liberdade; na verdade, a concepção de movimento histórico toma as formas como pauta (p.47). Toda conquista formal é, portanto, uma nova elaboração de toda a configuração histórica do teatro, razão pela qual, segundo o professor, "[...] nós hoje podemos dizer tranquilamente que não se pode fazer teatro sem o conhecimento teatral" (p.48). Um Brecht sem o conhecimento de Büchner, da farsa medieval e de Aristófanes certamente tirará de Brecht grande parte de seu potencial revolucionário.

O conhecimento da história do teatro - um conhecimento "empírico", por assim dizer jamais se separa de um conhecimento teórico. Haveria, em cada representação, a possibilidade de se pensar a própria natureza do teatro, sua essência. No momento em que um ator entra em cena, em jogo está uma grande tradição. Os pressupostos do teatro não ficam nos bastidores, mas são explicitados. Exemplo: a definição da representação teatral, esmiuçada por Professor e alunos, parece estar à busca de sua diferença específica. Representar é "[...] tornar novamente presente imagens e elementos" (p.90); mas, pondera Jacó Guinsburg,

no ato teatral, o prefixo 're' não exerce a função semântica de que está investido, pois, pela natureza do seu operador, cada vez que essa ação se representa, ela se constitui em um ato original, fundador do gesto, da palavra e da ação executados aqui e agora em relação ao vivo com o receptor (p. 90)

É tentador notar a semelhança entre a frase de Guinsburg e o pensamento de HansGeorg Gadamer sobre a natureza do espetáculo teatral ${ }^{1}$; a semelhança, aparentemente arbitrária, torna-se um pouco mais legítima quando se reconhece que Gadamer inseriu Hegel no centro da história da hermenêutica, posto habitualmente ocupado, nos manuais de filosofia, por Friedrich Schleiermacher.

Percebe-se, portanto, que em cada ato teatral há a possibilidade de se pensar o próprio teatro. E assim se costura o processo. Essa relação entre representação e conhecimento é muito bem discutida, por exemplo, quando Guinsburg põe em debate as diferenças e relações entre o lírico, o épico e o dramático, inspiradas no livro de Anatol Rosenfeld, $O$ teatro épico ${ }^{2}$, publicado, aliás, pela Editora Perspectiva, do próprio Jacó Guinsburg. Instigado novamente por Abílio Tavares, o professor novamente mostra como conhecimento e ação não podem ser separados. É um momento interessantíssimo da conversa, em que termos reservados ao vocabulário epistemológico (sujeito e objeto) tornam-se vivos no ambiente estético: no lírico, o "sujeito [...] quer apenas se expressar"; já "o sujeito épico relaciona-se com seu mundo como o intelecto se relaciona com o objeto de seu conhecimento: propõe-se a captá-lo nos seus limites precisos [...]"; e, por fim, no dramático, "[...] o mundo objeto apresenta-se como se o dramaturgo-autor se retirasse, por trás da rubricas, daquilo que possa vir a denunciá-lo como o titereiro criador daquele universo" (pp. 69-70). 
Mas a leitura da aula transcrita se torna mais densa quando passamos para o capítulo seguinte do livro: "Nos bastidores - Notas, apontamentos, ensaios e traduções". E ali pode ser percebido o esforço do professor em anotar a Estética de Hegel, a Poética de Aristóteles, a Obra de arte literária, de Roman Ingarden; percebe-se como deve ter sido próximo o diálogo com Anatol Rosenfeld. Percebe-se que a consciência, tão fluida durante a sala de aula, sempre pronta para uma resposta precisa e para uma pergunta aguda aos seus alunos, é, ela também, fruto de um devir.

O mais interessante é perceber, no meio dos apontamentos, como justamente o movimento é o mote das aulas de Jacó Guinsburg. Lá, misturam-se referências; e um autor é explorado não somente em seus conceitos que precisam ser transmitidos com clareza, mas, também, em suas sutilezas; um pensamento jamais se fixa em algum lugar ou dogma. Em suas notas sobre Ingarden, por exemplo, percebe-se que a arte precisa ser pensada como totalidade, mas logo se vê que a totalidade do fenômeno artístico de modo algum implica encapsulamento. Ou seja, "as palavras têm valor expressivo e são usadas como se fossem relações de cores e sons na pintura e na música, respectivamente. A camada verbal tem valor próprio e faz parte integral da obra [...]" (p. 213); mas sem esquecer jamais de que "o mundo humano, mesmo quando imaginário, tem valores outros além do estético, para o homem. Colocar a arte apenas como arte resulta em desvirtuar a sua função na sociedade" (p. 215).

Uma boa aula, portanto, precisa ser dinâmica, ou seja, ser capaz de criar novas soluções e apresentar novos problemas; de aprofundar e mostrar referências teóricas; de fazer novas combinações, inesperadas e surpreendentes; mas, acima de tudo, deve evitar o dogmatismo. Nas notas de aula, o leitor tem a chance de entrar em uma verdadeira oficina de teatro. São extremamente ricas as páginas sobre crítica teatral. Afinal, juntamente com a peça (e até mais do que os espetáculos), ela está presente no cotidiano das pessoas, nas páginas de jornal, e, hoje em dia, na internet. O importante é termos recursos não somente para poder vivenciar ao máximo um espetáculo, mas, também, para poder ler atentamente o texto crítico. Por exemplo:

[...] voltada para a peça, a crítica deve examiná-la não só em si, mas enquadrá-la, apontar seus defeitos e suas riquezas, desvendando seu potencial de atualidade ou perenidade [...] voltada para o público, cumpre-lhe de certo modo criá-lo, orientando-o não só sobre o que presta e o que não presta, mas ensinando-lhe a ver teatro não apenas como divertido, interessante ou chato, mas como uma arena de configuração de sua própria imagem na condição de homem e ser social atual e, quando possível, brasileiro [...] (pp. 230-231)

E, assim, o leitor conhece a senha para poder entrar na história das ideias críticas: Aristóteles, Ludovico Castelvetro ("vulgarizador" do Estagirista, por assim dizer), Ben Jonson, crítica psicológica - onde adquirimos elementos diversos para conhecer melhor a relação entre crítica e psicanálise, crítica e psicologia - e crítica sociológica, onde o professor destaca algo raríssimo no Brasil, a saber, a importância da obra de Johann 
Gottfried Herder, sobretudo, o seminal ensaio sobre Shakespeare, um marco fundador do historicismo amiúde desconhecido pelos próprios historiadores!

O caso da história das ideias críticas é apenas um dentre vários que poderiam ser destacados: as páginas sobre estilos e correntes também são muito ricas. De toda forma, sobressai o genuíno ímpeto formativo, o que já fora observado por Rosangela Patriota. O livro oferece também o ângulo histórico, no qual se conhece um momento da consciência da formação da intelectualidade brasileira, um indício

[...] dos referenciais que nortearam a formação de várias gerações de artistas e intelectuais no curso de Artes Cênicas da Escola de Comunicação de Artes da Universidade de São Paulo, além de abrir um capítulo muito instigante no que tange à História da Leitura do Brasil, pois o repertório mobilizado pelo professor está em consonância com o debate intelectual do país das décadas de 1960, 1970 e 1980 (p. 29).

O livro, porém, não apresenta um sistema conceitual, de perfeito acabamento, da história intelectual; é um momento vivo, pois, nas palavras do próprio Jacó Guinsburg lembradas por Abílio Tavares, "a própria vida se revolta contra a escritura. Ela não foi feita para ser escrita” (p. 448). O livro simplesmente dá o material para o leitor se sentir um pouco como os alunos da USP que, por vezes, olhavam de fora o transcorrer da aula. Mas, ainda assim, nos é possível ainda, mesmo olhando pela fechadura, participar de um conhecimento testemunhado por seus alunos, o que provavelmente é mais rico do que esquemas interpretativos cujas pretensões de totalidade mal dissimulam seu viés interpretativo pouco afeito ao debate. De posse dos elementos para traçar parte da história artística e intelectual, o leitor passa a ter instrumentos para criar aquilo que, segundo Jacob Burckhardt ${ }^{3}$, era a maior tarefa da história da cultura: criar uma imagem da continuidade, tirando, assim, o Homem da barbárie.

É comum na cultura intelectual brasileira a alergia pela teoria. E vários dos depoimentos presentes em "A Cena em aula" mostram que nossa aversão pela reflexão teórica precisa ser revista. Não há razão para ter medo da teoria, conforme diz Antonio Araújo:

O professor Jacó instigava-nos uma paixão pela teoria do teatro não em nome de alguma exigência curricular mínima ou de um eventual lustro intelectual. Ele nos fazia perceber que os escritos estéticos ou as análises históricas não eram letra-morta, mas instrumentos capazes de agir sobre nossas experimentações em sala de ensaio. Não que ele reduzisse a teoria à sua mera instrumentalização ou pragmatismo. Ou seja, não se tratava de uma teoria aplicada, mas sim, o encontro com a potência criadora e geradora do pensamento e da reflexão (p. 449)

É até injusto destacar este ou aquele depoimento, e apenas me limito a dar ao leitor alguns indícios dos testemunhos de formação dos alunos de Jacó Guinsburg. Percebemos, mediante o texto de Armando Sérgio da Silva (p. 451), a importância da ousadia do professor em não abrir mão da discussão de textos complexos, algo fundamental na universidade, ainda mais na universidade brasileira que, por vezes, 
demagogicamente passa textos "acessíveis", quando, na verdade, sonega conhecimento, tratando os alunos como seres incapazes de ter contato com a alta cultura. Conferimos também, pelo depoimento de Cibele Forjaz (pp.457-458), como a universidade não pode se restringir à obrigatoriedade burocrática de horários e aulas: as lições do professor Jacó Guinsburg invariavelmente ultrapassavam o horário regulamentar, e se estendiam em grupos de estudo. E, para ficar em só mais um exemplo, sabemos como Gabriel Vilela "deixou de comer trevas" após as aulas de Jacó Guinsburg, aprendendo, com ele, algo imprescindível para o seu trabalho de diretor de teatro.

Não é motivo para espanto tal recepção por parte dos alunos. O professor demonstra uma impressionante serenidade em suas lembranças dos tempos de sala de aula; de como chegou até lá, de como conduzia e preparava seus cursos. A entrevista feita por Rosangela Patriota, chamada "O rememorar de um ofício - Um professor em devir", demonstra uma cristalina consciência de todo o processo, desde os tempos de militância política e de aprendizagem como mecânico e tecelão, passando pela fundação de sua primeira editora (Rampa) e realização das primeiras traduções até a consciência do propósito de um professor. De maneira generosa, "A Cena em sala" regala o leitor com o ângulo de Jacó Guinsburg sobre sua própria trajetória.

A entrevista é saborosa: nela, suspeitamos que o dinamismo das aulas de Jacó Guinsburg tem origem no profundo tédio sentido quando o professor sentava ainda nos bancos da sala de aula: "Eu não gostava da rigidez da Escola", diz Guinsburg. E continua: "Só queria estudar o que me interessava. As grades horárias me aborreciam: uma hora era aula de Matemática, no momento seguinte estávamos em uma aula de Português" (p. 513). Ainda jovem, já sabia qual o "motor de arranque" para o estudo e para o aprendizado: o interesse. Na verdade, é de dar arrepios, pois, em nossos dias, as grades curriculares são sufocantes mesmo nas universidades. Melhor sorte tiveram os alunos de Estética Teatral da USP, pois não encontraram um professor dogmático, mas um professor capaz de lhes dar condições para desenvolverem e terem consciência de seus próprios interesses. Mas isto só é possível com o genuíno sentido da palavra erudição. Nada de poeiras e listas de nomes, mas uma apresentação viva de uma gama de possibilidades, nas quais o aluno pode enveredar, parar, retornar, recomeçar, avançar. Por esta razão, discordo do professor quando ele diz que faz um sobrevoo desengajado. O engajamento só é possível, ou é mais vigoroso, com o sobrevoo.

Apenas uma ressalva: o leitor mais curioso sente a falta, em algumas ocasiões, de referências bibliográficas que poderiam nortear estudos posteriores. Para ficar em um exemplo: ao citar a comparação de Lessing entre o dramaturgo e o historiador - na qual somente no teatro o passado aconteceria novamente aos olhos do presente - alguém mais curioso certamente desejaria saber em que passagem ou em qual livro Lessing fez tal comparação (p. 74). Ou ainda quando, em uma de suas notas, Jacó Guinsburg cita longo trecho de uma obra de Anatol Rosenfeld, mas o leitor fica à espera de alguma 
referência (p. 151). Mas são apenas sugestões para uma próxima edição de uma obra importantíssima não somente para os estudantes de história do teatro e de estética teatral, mas para todos os interessados na cultura brasileira sob um ponto de vista cosmopolita e formativo.

* Pedro Caldas é professor adjunto do Departamento de História da UniRio.

${ }^{1}$ Cf. GADAMER, H.-G. Wahrheit und Methode: Grundzüge einer philosophischen Hermeneutik. Tübingen: Mohr, 1990, 6a. ed, p.152.

${ }^{2}$ Cf. RosenfELD, A. O teatro épico. São Paulo: Perspectiva, 2004, 4a. ed.

${ }^{3}$ Cf. BURCKHARDT, J. Grieschiche Kulturgeschichte. Band 1: Die Griechen und ihr Mythus/ Die Polis. In: Kritische Gesamtausgabe. Band 19. München: Beck; Basel: Schwabe \& Co., 2002, p. 371. 